Gut, 1973, 14, 800-804

\title{
A case of active chronic hepatitis with painless erosive arthritis
}

\author{
D. E. BARNARDO ${ }^{1}$, B. VERNON-ROBERTS, AND H. L. F. CURREY \\ From the Departments of Gastroenterology, Morbid Anatomy, and Rheumatology, The London Hospital, \\ London
}

SUMMARY True arthritis is very much less common than arthralgia in patients suffering from active chronic hepatitis and only scanty information is available about the joint changes in this disease. We report here the case of a young woman with active chronic hepatitis complicated by a painless, erosive small joint arthropathy.

\section{Presentation}

While on holiday in Spain in 1966, the patient (then aged 17 years) developed nausea, upper abdominal pain, night sweats, an unproductive cough, and dyspnoea. These symptoms persisted and, six weeks after their onset, she became jaundiced with dark urine and pale stools. Four weeks later, she was referred for investigation of continuing jaundice. Examination revealed a generally healthy looking girl, with icterus, palmar erythema, finger-nail clubbing, hepatosplenomegaly, and a right-sided pleural effusion. The serum level of bilirubin ranged from 4.1 to $12.0 \mathrm{mg} / 100 \mathrm{ml}$, the aspartate transaminase was consistently elevated to about 600 units/ $100 \mathrm{ml}$, and the alkaline phosphatase was $16 \mathrm{KA}$ units $/ 100 \mathrm{ml}$. Initially, no autoantibodies or LE cells were detected in her peripheral blood; later, LE cells were seen, antinuclear factor appeared in a titre of $1: 10$, smooth muscle (but not mitochondrial) antibody was identified, and the direct Coombs test became positive. There was a diffuse increase in gamma globulin (total globulin $4.0 \mathrm{~g} / 100 \mathrm{ml}$ ). A pleural biopsy showed non-specific inflammatory changes and the pleural fluid was sterile. Liver biopsy revealed normal general architecture, but there was expansion of the portal tracts which contained a moderate infiltrate of lymphocytes, macrophages, and occasional neutrophil polymorphs; in many areas this infiltrate extended into the adjacent parenchyma. The hepatocytes (some

'Reprint requests to: Dr. D. E. Barnardo, Physician, Medical Unit,
Queen Mary's Hospital, Roehampton, London, SW15.

Received for publication 17 July 1973. binucleate) were markedly swollen, and scattered acidophil bodies and bile thrombi were present.

There was a diffuse intralobular infiltrate composed of mononuclear cells, but plasma cells were absent throughout. Centrilobular and focal condensation of reticulin was present with septae extending from the portal tracts (fig 1). A histological diagnosis was made of acute viral hepatitis.

\section{Subsequent Course}

Over the succeeding six years, the patient has shown evidence of continuing active liver disease. Also, apart from arthritis (see below), she has suffered from episodes of fever, secondary amenorrhoea, pleural effusions, diarrhoea, and ulceration of the lower legs. Hypoprothrombinaemia, thrombocytopenia, and ascites have precluded further liver biopsies, but the general pattern of disease was felt to indicate a diagnosis of active chronic hepatitis with cirrhosis. Prednisone (taken over the past five years in doses ranging from $10 \mathrm{mg}$ to $40 \mathrm{mg}$ daily) has clearly produced some suppression of both clinical and biochemical abnormalities. Screening of other organs for concomitant 'autoimmune' disease has revealed no evidence of kerato-conjunctivitis sicca, thyroid or adrenal dysfunction, but incomplete renal tubular acidosis was present. Investigations carried out during 1971 showed that neither the hepatitis associated (Australia) antigen (HAA) nor the epidemic hepatitis-associated (Milan) antigen was present in her serum, and negative tests were obtained for serum DNA antibodies (Pincus, Schur, Rose, Decker, and Talal, 1969) and complement degradation products 


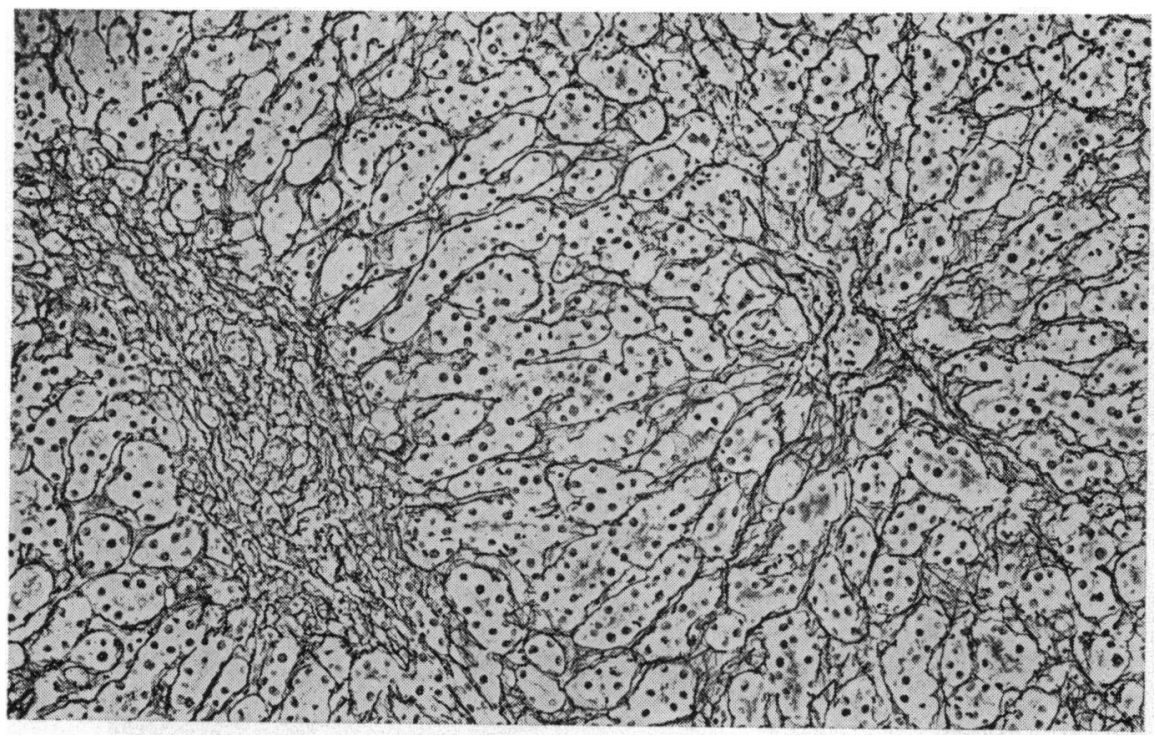

Fig 1 Liver biopsy showing centrilobular condensation of reticulin, swelling of hepatocytes, and expansion of portal tract. Gomori's reticulin. $\times 200$.
(West, Winter, Forristal, McConville, and Davis, 1967; Ngu and Soothill, 1969). However, serial determinations of the serum levels of $\mathrm{C}_{3}$ and $\mathrm{CH}_{50}$ fractions of complement have given persistently low values (see table).

\begin{tabular}{lll}
\hline & $\begin{array}{l}\mathrm{C}_{\mathbf{z}} \\
(\mathrm{ng} / 100 \mathrm{ml})\end{array}$ & $\begin{array}{l}\mathrm{CH}_{\text {so }} \\
(\text { units } / \mathrm{ml})\end{array}$ \\
\cline { 2 - 3 } & Normal Range \\
\cline { 2 - 3 } & $127-163$ & $32-50$ \\
\hline Dec 1970 & 88 & 26 \\
Feb 1971 & 88 & 32 \\
April 1971 & 100 & 26 \\
July 1971 & 72 & 27 \\
Oct 1971 & 76 & 30 \\
Dec 1971 & 65 & 30 \\
\hline
\end{tabular}

Table Values obtained for the $\mathrm{C}_{3}$ and $\mathrm{CH}_{50}$ fractions of serum complement on various occasions

\section{The Arthropathy}

Arthritis appeared for the first time in April 1970, four years after the onset of the disease. Over the course of a few weeks, a number of peripheral small joints gradually swelled until the hands presented a striking clinical appearance (fig 2a). In the affected joints, the swelling was spongy and compressible and the overlying skin was warm and dusky purple. Impressively, the range of movements was full and quite painless and there was no tenderness. The affected joints in the left hand were the proximal interphalangeal joint of the index finger and the metacarpophalangeal joint of the thumb; in the right hand, the distal interphalangeal joints of the index, ring, and little fingers, the proximal interphalangeal joint of the middle finger, and the metacarpophalangeal joint of the thumb were similarly affected; also, the third proximal interphalangeal joint in both feet.

Tests for rheumatoid factor (Rose-Waaler and tube latex) were negative at the onset of the arthritis and have remained so. Radiographs of the affected joints (figs 3 and 4) showed striking destructive and erosive changes with some periosteal new bone formation. The arthritis persisted for 10 months, then resolved spontaneously, leaving the joints clinically virtually normal (fig 2b). During this period, the general clinical and biochemical evidence of disease, and her steroid requirements, continued to fluctuate in a manner which did not mark this period as being in any way different from the former or subsequent course.

In April 1970 (at a time when marked swelling was present) an open biopsy was carried out on the right middle proximal interphalangeal joint. The synovium appeared grossly thickened and oedematous. Light microscopy revealed moderate villous proliferation, but the most striking feature was the presence of abundant fibrinoid material on and within the surface synovial (intimal) layer, replacing it in many areas (fig 5). In places, palisaded histiocytes abutted onto the deep surface of the fibrinoid in a manner resembling the periphery of a classic rheumatoid nodule. There was active proliferation of new blood vessels in the subsynovial tissues and a heavy diffuse infiltrate of plasma cells, together with occasional lymphocytes and histiocytes. Electron microscopy revealed the presence of abundant non- 


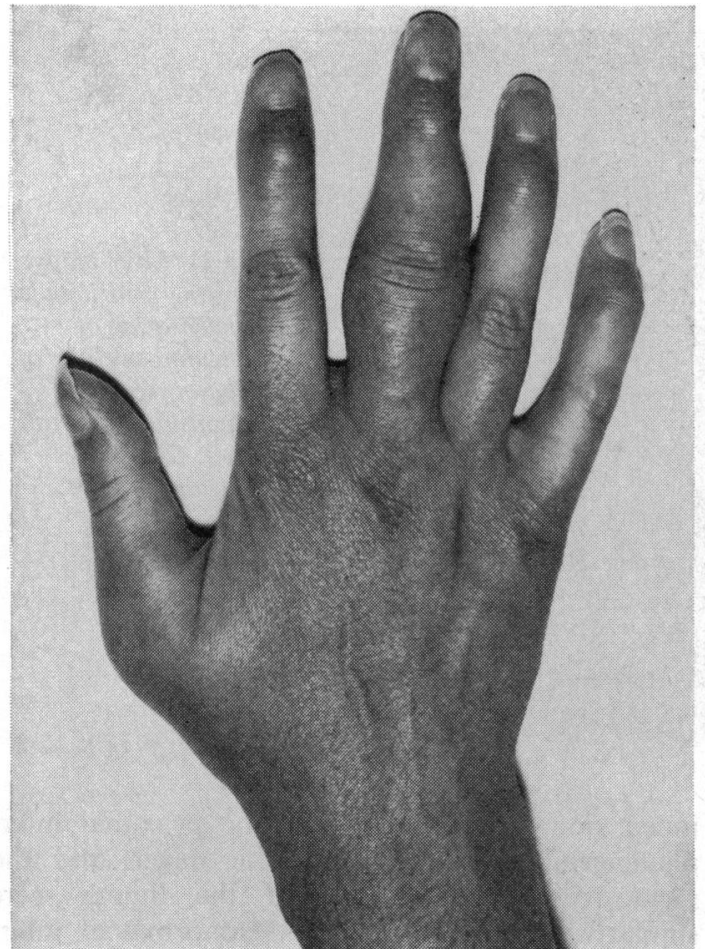

a

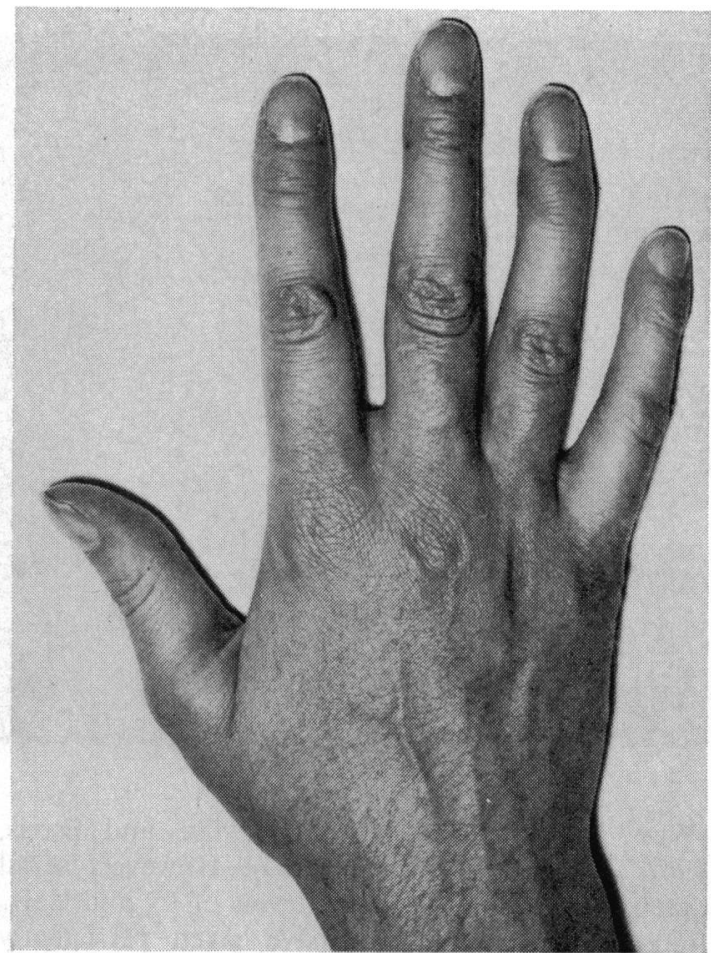

b

Fig 2 The right hand (a) August 1970; marked swelling of the thumb MCP and middle finger proximal interphalangeal joints. There is some swelling also of the index, ring, and little finger TIP joints, (b) December 1971; clinically normal hand.

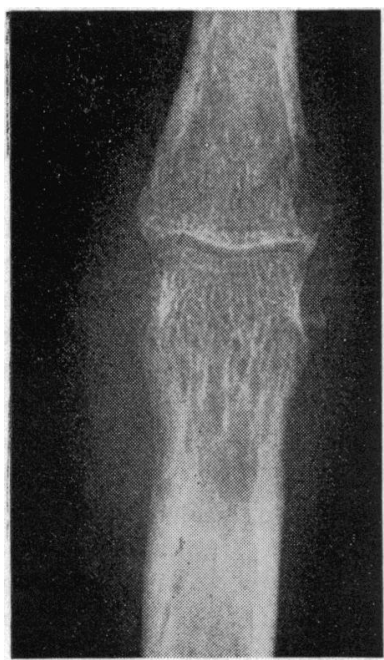

Fig 3

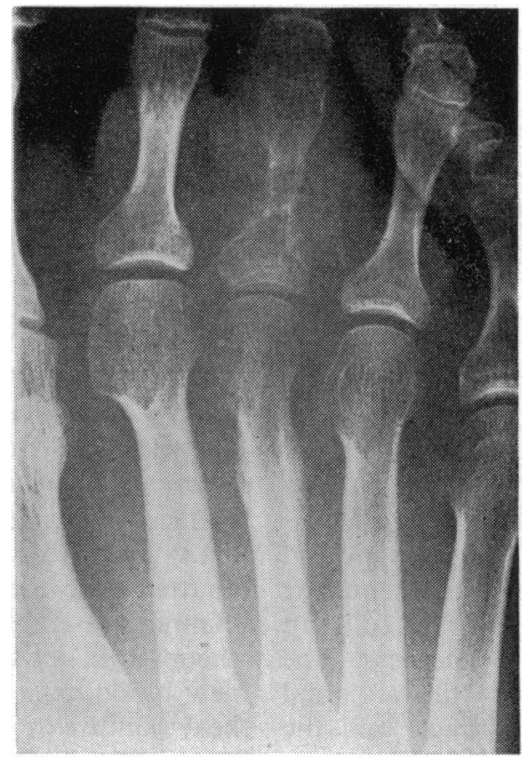

Fig 3 Radiograph of the right middle finger proximal interphangeal joints in April 1970: erosions and local porosis.

Fig 4 Radiograph of right third toe metatarsophalangeal joint in April 1970: periarticular porosis, erosions of the metatarsal head, and periosteal new bone formation in the shaft. 


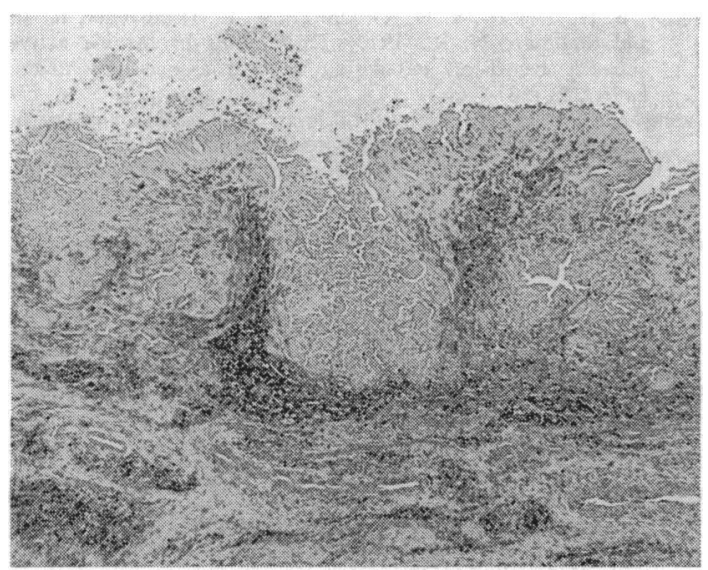

Fig 5 Synovium showing surface deposit of amorphous fibrinoid material and cellular infiltrate in underlying tissue. Haematoxylin and eosin. $\times 120$.

collagenous dense filamentous material and scattered collagen fibres in the surface fibrinoid, the appearances being similar to those in the centre of a rheumatoid nodule. Although the biopsy specimen had unfortunately been immersed in formol saline for four hours, immunofluorescence revealed the presence of abundant IgG, small amounts of IgM, and a moderate amount of $\mathrm{C}_{3}$ complement in the surface fibrinoid. It was felt that these features suggested the possibility of immune complex deposition on the synovium.

\section{Discussion}

The protracted illness with evidence of continuing liver disease, involvement of multiple systems, and the pattern of autoantibodies present in the serum suggest that this patient suffers from active chronic hepatitis, a syndrome which may well include conditions of varying pathogenesis (Bulkley, Heizer, Goldfinger, Isselbacher, and Shulman, 1970; Wright, 1971).

Arthritis may occur in association with a variety of liver diseases (Whelton, 1970), including a transient polyarthritis presenting in the prodromal phase of acute viral hepatitis and thought to be a serum-sickness-like syndrome caused by circulating immune complexes (Alpert, Isselbacher, and Schur, 1971; Onion, Crumpacker, and Gilliland, 1971). Less well defined is the arthropathy which may occur, as in this case, in association with active chronic hepatitis. Authors who have studied this condition report an incidence of joint complaints which has varied from $10 \%$ to over $50 \%$ (Bearn, Kunkel, and Slater, 1956; Bartholomew, Hagedorn, Cain, and
Baggenstoss, 1958; Willcox and Isselbacher, 1961; Mackay and Wood, 1962; Read, Sherlock, and Harrison, 1963; Mistilis, Skyring and Blackburn, 1968; Whelton, 1970). Generally, joint complaints. have been reported to wax and wane in parallel with other features of the disease, and arthralgia is more common than true arthritis (although the former may be accompanied by swelling of periarticular structures and erythema). Radiological erosions and joint changes suggestive of rheumatoid arthritis have been reported (Bearn et al, 1956; Mistilis et al, 1968; Whelton, 1970) and the frequency with which antiglobulins are present in the serum of patients with active hepatocellular disease (Bouchier, Rhodes, and Sherlock, 1964) greatly reduces the diagnostic value of serological tests for rheumatoid factors in these circumstances. Large limb joints are reported to be involved more frequently than the small joints of the hands and feet.

The striking features of the arthritis seen in this case were the very marked soft tissue swelling and gross bone destruction occurring in joints which were completely painless and had a full range of movement. Unlike other reports, this arthropathy was limited to small joints of the hands and feet. Moreover, its appearance was not associated with any deterioration in liver function and it resolved spontaneously without change in therapy.

The microscopic appearances of the synovium were also striking. The cellular infiltration is not unlike that seen in many cases of rheumatoid arthritis, while the surface deposition of fibrinoid material is reminiscent of the changes in the synovium of some patients with systemic lupus erythematosus (Cruickshank, 1959; Labowitz and Schumacher, 1971). However, the present case showed neither true vasculitis nor haematoxylin bodies. These morphological changes must be regarded as non-specific and they do not, in themselves, establish the pathogenesis of the synovitis. Although the immunofluorescent studies were, unfortunately, hampered by brief immersion of the tissue in formol saline, the findings are in keeping with there having been a deposition of immune complexes on the surface of the synovium, and are in agreement with the hypothesis that this is the mechanism of arthritis in active chronic hepatitis. Two components of serum complement have been consistently reduced in this patient (levels were not measured before or during the onset of the arthritis). In acute hepatitis, $\mathrm{C}_{3}$ and $\mathrm{CH}_{50}$ components of serum complement are often reduced (Alpert et al, 1971; Fox, Dudley, and Sherlock, 1971); this is thought to reflect impaired hepatic synthesis. In chronic liver disease, serum levels of complement are usually normal (Fox et al, 1971), although low 
$\mathrm{C}_{3}$ and $\mathrm{CH}_{50}$ levels have been reported and attributed to increased consumption (Maclachlan, Rodnan, Cooper, and Fennell, 1965).

The synovial appearances in this case would suggest that immune complexes may have been deposited during the acute arthritis. However, the fact that complement degradation products were not detected in the serum after the arthritis had settled and that since then serum complement levels have been consistently subnormal suggests that, at the present time, there is impaired hepatic synthesis rather than increased consumption of complement.

Dr Salvatore del Prete, University of Milan, kindly undertook the examination for the Milan antigen; Dr Graham Hughes, Hammersmith Hospital, London, kindly tested the serum for DNA antibodies; Dr Keith Peters, Hammersmith Hospital, London, kindly examined the serum for complement degradation products.

\section{References}

Alpert, E., Isselbacher, K. J., and Schur, P. H. (1971). The pathogenesis of arthritis associated with viral hepatitis: complement component studies. New Engl. J. Med., 285, 135-189.

Bartholomew, L. G., Hagedorn, A. B., Cain, J. C., and Baggenstoss, A. H. (1958). Hepatitis and cirrhosis in women with positive clot tests for lupus erythematosus. New Engl. J. Med., 259, 947-956.

Bearn, A. G., Kunkel, H. G., and Slater, R. J. (1956). The problem of chronic liver disease in young women. Amer. J. Med., 21, 3-15.

Bouchier, I. A. D., Rhodes, K., and Sherlock, S. (1964). Serological abnormalities in patients with liver disease. Brit. med. J., 1, 592-594.
Bulkley, B. H., Heizer, W. D., Goldfinger, S. E., Isselbacher, K. J., and Shulman, N. R. (1970). Distinctions in chronic active hepatitis based on circulating hepatitis-associated antigen. Lancet, 2, 1323-1326.

Cruickshank, B. (1959). Lesions of joints and tendon sheaths in systemic lupus erythematosus. Ann. rheum. Dis., 18, 111-119.

Fox, R. A., Dudley, F. J., and Sherlock, S. (1971). The serum concentration of the third component of complement $\beta I C / \beta I A$ in liver disease. Gut, 12, 574-578.

Labowitz, R., and Schumacher, H. R., Jr. (1971). Articular manifestations of systemic lupus erythematosus. Ann. intern. Med., 74, 911-921.

Mackay, I. R., and Wood, I. J. (1962). Lupoid hepatisis: a comparison of 22 cases with other types of chronic liver disease. Quart. J. Med., 31, 485-507.

Maclachlan, M. J., Rodnan, G. P., Cooper, W. M., and Fennell, R. H., Jr. (1965). Chronic active ("lupoid") hepatitis: a clinical, serological, and pathological study of 20 patients. Ann. intern. Med., 62, 425-462.

Mistilis, S. P., Skyring, A. P., and Blackburn, C. R. B. (1968). Natural history of active chronic hepatitis. 1. Clinical features, course, diagnostic criteria, morbidity, mortality and survival. Aust. Ann. Med., 17, 214-223.

Ngu, J. L., and Soothill, J. F. (1969). Immunoconglutinin and complement changes in children with acute nephritis. Clin. exp. Immunol., 5, 557-566.

Onion, D. K., Crumpacker, C. S., and Gilliland, B. C. (1971). Arthritis of hepatitis associated with Australia antigen. Ann. intern. Med., 75, 29-33.

Pincus, T., Schur, P. H., Rose, J. A., Decker, J. L., and Talal, N. (1969). Measurement of serum DNA-binding activity in sys emic lupus erythematosus. New Engl. J. Med., 281, 701-705.

Read, A. E., Sherlock, S., and Harrison, C. V. (1963). Active 'juvenile' cirrhosis considered as a part of a systemic disease and the effect of corticosteroid therapy. Gut, 4, 378-393.

West, C. D., Winter, S., Forristal, J., McConville, J. M., and Davis, N. C. (1967). Evidence for in vivo breakdown of $\beta$ IC-globulin in hypocomplementemic glomerulonephritis. J. clin. Invest., 46, $539-548$.

Whelton, M. J. (1970). Arthropathy and liver disease. Brit. J. hosp. Med., 3, 243-247.

Willcox, R. G., and Isselbacher, K. J. (1961). Chronic liver disease in young people. Amer. J. Med., 30, 185-195.

Wright, R. (1971). The Australia antigen in chronic active hepatitis. Proc. roy. Soc. Med., 64, 276-277. 